Open Access

\title{
Personalizing mechanical ventilation according to physiologic parameters to stabilize alveoli and minimize ventilator induced lung injury (VILI)
}

Gary F. Nieman ${ }^{1}$, Joshua Satalin ${ }^{1,5^{*}}$ (D), Penny Andrews ${ }^{2}$, Hani Aiash ${ }^{1}$, Nader M. Habashi ${ }^{3}$ and Louis A. Gatto ${ }^{4}$

\author{
* Correspondence: \\ satalinj@upstate.edu \\ 'Department of Surgery, SUNY \\ Upstate Medical University, \\ Syracuse, NY, USA \\ ${ }^{5}$ Cardiopulmonary Critical Care Lab, \\ Department of Surgery, Upstate \\ Medical University, 750 East Adams \\ Street, Syracuse, NY 13210, USA \\ Full list of author information is \\ available at the end of the article
}

\begin{abstract}
It has been shown that mechanical ventilation in patients with, or at high-risk for, the development of acute respiratory distress syndrome (ARDS) can be a double-edged sword. If the mechanical breath is improperly set, it can amplify the lung injury associated with ARDS, causing a secondary ventilator-induced lung injury (VILI). Conversely, the mechanical breath can be adjusted to minimize VILI, which can reduce ARDS mortality. The current standard of care ventilation strategy to minimize VILI attempts to reduce alveolar over-distension and recruitment-derecruitment (R/D) by lowering tidal volume (Vt) to $6 \mathrm{cc} / \mathrm{kg}$ combined with adjusting positive-end expiratory pressure (PEEP) based on a sliding scale directed by changes in oxygenation. Thus, Vt is often but not always set as a "one-size-fits-all" approach and although PEEP is often set arbitrarily at $5 \mathrm{cmH}_{2} \mathrm{O}$, it may be personalized according to changes in a physiologic parameter, most often to oxygenation. However, there is evidence that oxygenation as a method to optimize PEEP is not congruent with the PEEP levels necessary to maintain an open and stable lung. Thus, optimal PEEP might not be personalized to the lung pathology of an individual patient using oxygenation as the physiologic feedback system. Multiple methods of personalizing PEEP have been tested and include dead space, lung compliance, lung stress and strain, ventilation patterns using computed tomography $(\mathrm{CT})$ or electrical impedance tomography (EIT), inflection points on the pressure/volume curve (PN), and the slope of the expiratory flow curve using airway pressure release ventilation (APRV). Although many studies have shown that personalizing PEEP is possible, there is no consensus as to the optimal technique. This review will assess various methods used to personalize PEEP, directed by physiologic parameters, necessary to adaptively adjust ventilator settings with progressive changes in lung pathophysiology.
\end{abstract}

Keywords: ARDS, VLI, Personalizing mechanical ventilation, Open lung ventilation, PEEP

\section{Review}

Improvements in protective mechanical ventilation strategies have reduced mortality secondary to the acute respiratory distress syndrome (ARDS) from almost certain death $(\sim 70 \%)$ to the current mortality rate of $\sim 40 \%$ [1] in the moderate to severe form of the disease [2]. Although some studies have shown a reduction in ARDS mortality [3], a recent review of the literature concluded that ARDS mortality rate remains 
unchanged and has not been reduced for almost 15 years [1, 4]. Thus, research emphasis has shifted from treating to preventing ARDS using preemptive ventilator strategies applied to the normal lung in patients at high-risk [5, 6]. Preemptive ventilator strategies, although not definitive, have been shown to reduce the complications of mechanically ventilated patients with the believed mechanism to be maintaining an open, homogeneously ventilated lung, and minimizing repetitive alveolar collapse and expansion (RACE) with each breath. However, existing preemptive strategies use the same "one-size-fits-all" approach that is currently used to treat established ARDS [7] and have not yet shown a clear reduction in ARDS incidence. Many physicians do not strictly stay with the recommended $6 \mathrm{cc} / \mathrm{kg}$ for all patients but make adjustment using their clinical knowledge to adjust Vt to better match the need of the patient. Moreover, PEEP and $\mathrm{FiO}_{2}$ are adjusted in reaction to changes in oxygenation, which has been shown not to correlate well with pathologic changes in lung mechanics that are known to cause ventilator-induced lung injury (VILI) $[8,9]$.

Optimization of the protective mechanical breath could be achieved if a closed-loop feedback system existed, in which the physician analyzes changes in lung physiology and uses this as feedback to adjust ventilator settings, with the goal to maintain an open and stable lung regardless of the degree of lung pathology (Fig. 1) [10, 11]. Since both alveolar opening and collapse time constants vary depending on lung injury severity and evolve as the lung pathology improves or deteriorates, ventilator settings must be constantly adjusted to fit the specific needs of the individual [12-19]. The components that comprise the Mechanical Breath Profile $\left(\mathrm{MB}_{\mathrm{P}}\right)$ (i.e., airway pressures, flows, volumes, rates, and the duration that they are applied during each breath) have been targeted for personalization [20-22], but personalized PEEP has been the most studied. Multiple studies have reviewed or tested methods to apply PEEP using the

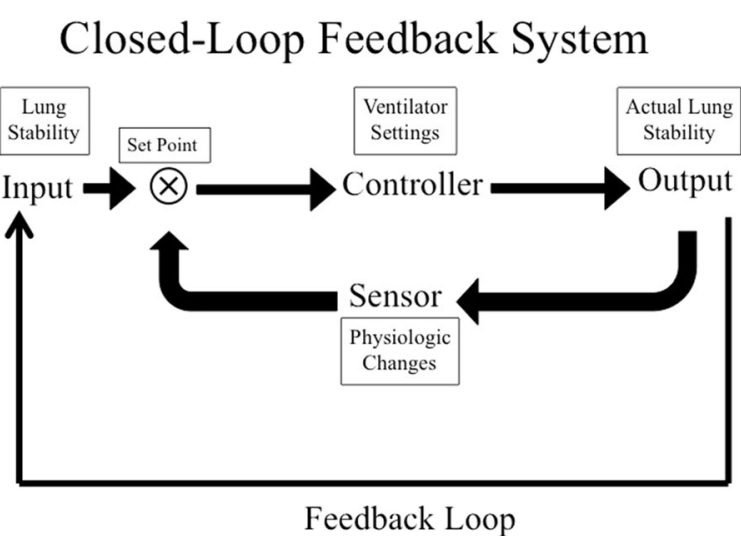

Fig. 1 A schematic of a closed-loop feedback system that would adaptively modify ventilator settings necessary to maintain lung stability. The input is the key physiologic parameter that will be maintained by the feedback system; in this case lung stability. The set point is the parameter on the ventilator that will be adjusted to maintain the input as required. The controller is what will be adjusted to maintain the set point; in this case ventilator setting such as tidal volume and PEEP. The output is the desired physiologic effect; in this case actual lung stability. The key component of a functional feedback system is the presence of a sensor that can identify if the output is less than desirable and readjust the set point to bring the output back into compliance. Physiologic changes in lung function, such as oxygenation, dead space, lung compliance, infection points on the pressure/volume curve, stress index, imaging, or slope of the expiratory flow curve, can be used as the sensor to maintain the desired input 
pathology of the lung [23-30]. However, no consensus has been reached on what that optimal strategy is that can lead to the personalization of PEEP in the protective mechanical breath.

In order to determine that strategy, the mechanism by which positive pressure ventilation injures lung tissue must first be understood. Thus, this review will discuss the current postulated mechanisms of VILI at the alveolar level. Using our understanding of the dynamic pathophysiology that occurs in the microenvironment (i.e., alveoli and alveolar ducts), we can form hypotheses on the optimal method of personalizing PEEP necessary to prevent progressive acute lung injury (ALI). Setting the ideal PEEP to stabilize the lung is an important parameter in reducing VILI and will be the focus of this review, it must be remembered that the entire $M_{P}$ must be adjusted properly to maximize lung protection.

\section{Mechanisms of VILI in the microenvironment-alveoli and alveolar ducts}

Although there is still debate [31], there is a great deal of literature supporting three mechanisms by which alveoli and alveolar ducts are injured during mechanical ventilation: (1) over-distension (OD) [32]; 2) dynamic recruitment and derecruitment (R/D) causing a significant dynamic strain with each breath; and (3) stress-concentration (S-C) that occurs between open and collapse or edema-filled alveoli (Fig. 2) [33, 34]. Tissue damage, secondary to these mechanical injuries, results in a secondary inflammatory injury known as biotrauma [35], which exacerbates the primary mechanical injury. However, it remains unknown which of these three mechanisms plays the greatest role in VILI pathology. This critical information is needed to determine how PEEP should be applied when attempting to block the most injurious VILI component(s). The following is a review on the relative importance of each of the above VILI mechanisms.

\section{Alveolar over-distension (OD)}

It is well known that ARDS causes a heterogeneous injury with collapsed or edemafilled lung adjacent to normal lung tissue. Ever since the publication of the clinical trial showing that low tidal volume (Vt) reduced ARDS mortality, the presumed mechanism for this protection was a reduction in over-distension of the normal lung tissue [7]. Gattinoni et al. reinforced this hypothesis using the term 'Baby Lung' for the remaining normal lung tissue in patients with ARDS. They hypothesized that the majority of the Vt would be delivered to the more compliant normal [baby] lung, thereby causing tissue injury by over-distension [32]. Most of the data supporting alveolar OD as a mechanism of VILI did not directly measure the change in alveolar size but rather the change in lung tissue density measured using computerized tomography (CT) [36]. Using CT, lung parenchyma is classified as a gas/tissue ratio in four categories: (1) notinflated; (2) poorly inflated; (3) well-inflated; and (4) overinflated [33, 36]. Lung areas in the overinflated 'Baby Lung' category are hypothesized to be the tissue damaged during tidal ventilation, thus, reducing Vt would reduce tissue stretch and VILI and is believed to be the mechanism for the reduced mortality using low Vt ventilation [7].

However, a great deal of literature supports the concept that over-distension in normal lung tissue (i.e., Baby Lung) will not cause the histopathology typical of VILI, although it may cause tears in airways leading to a pneumothorax. Direct assessment of alveolar size change, using multiple techniques, have shown that alveoli do not expand 


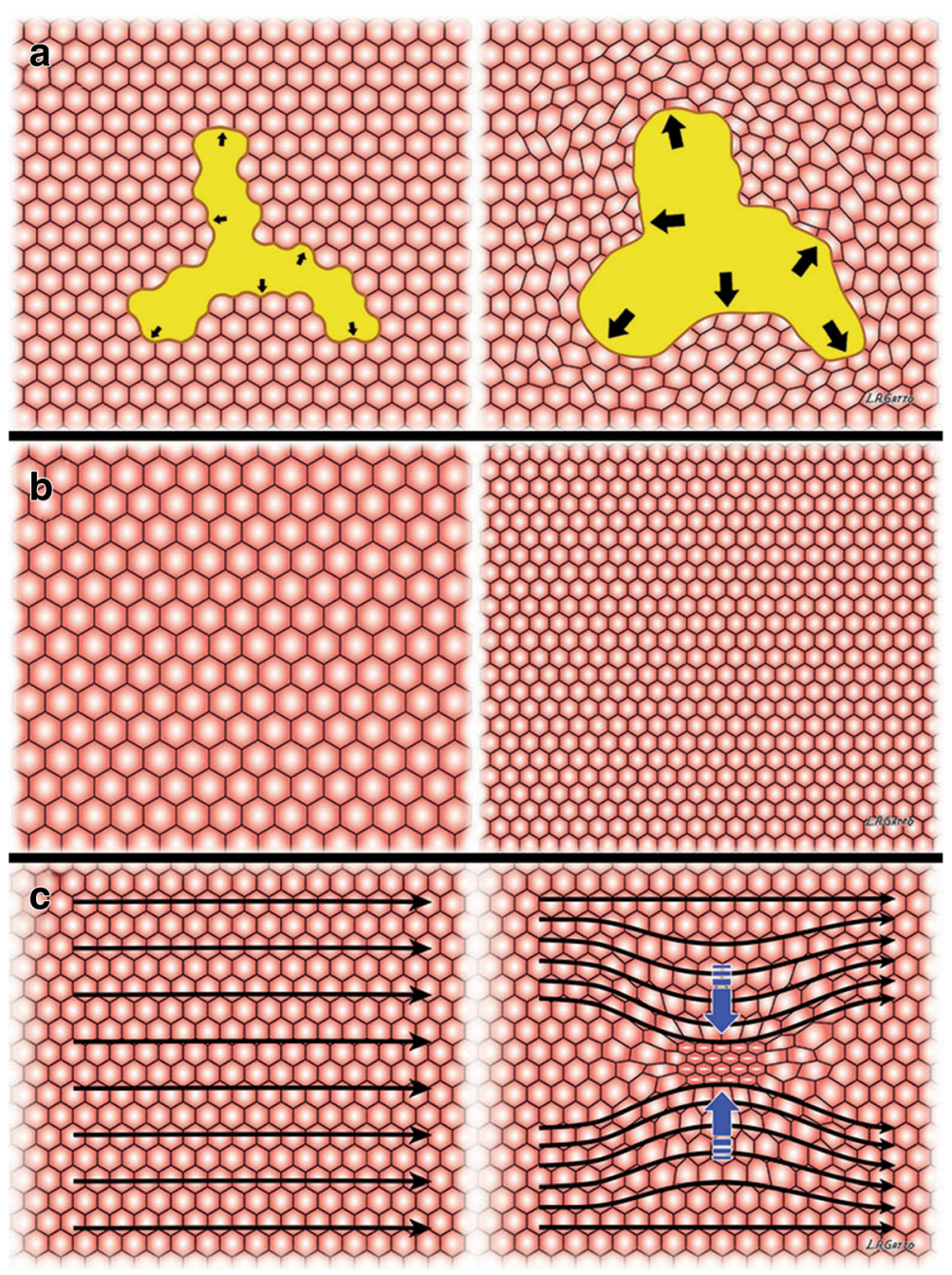

Fig. 2 The three mechanical mechanisms of ventilator-induced lung injury (VILI) include: a over-distension of tissue caused by excessive volume and pressure, $\mathbf{b}$ alveolar collapse and reopening with each breath secondary to surfactant deactivation, which causes a dynamic strain-induced tissue trauma, and c stressconcentrators caused by heterogeneous ventilation with open alveoli adjacent to collapsed or edema-filled alveoli. a An alveolar duct (yellow) is shown surrounded by alveoli represented by hexagons. Low volume/ pressure (small arrows) do not over-distend alveolar ducts or distort surrounding alveoli. High volume/pressure (large arrows) over-distend alveolar ducts and distort surrounding alveoli that can lead to stress-failure in these tissues [40]. b Surfactant deactivation is a hallmark of ARDS and will result in alveolar collapse at end expiration and reopening during inspiration. Following loss of surfactant function at inspiration alveoli (hexagons) are fully inflated. However, unless end expiratory pressure is increased alveoli collapse at expiration (hexagons significantly reduced in size). This alveolar recruitment/derecruitment with each breath causes severe shear stress-induced tissue trauma $[116,117]$. c Homogeneous ventilation is represented by uniformly open alveoli (hexagons) and the interdependence of these alveoli with shared wall results in a very stable structure [118]. Internal force lines (black arrows) are uniform across the homogeneously inflated lung tissue. [119]. Heterogeneous Ventilation, where isolated areas of alveolar collapse occur (blue arrows) disrupts the stability of alveolar interdependence such that stress is no longer evenly distributed across the tissue. Thus, heterogeneous tissue inflation causes a significant concentration of stress in the areas surrounding the collapse. Internal force lines bow in toward the collapsed alveoli and concentrate the stress, represented by the black stress lines becoming closer together, around the area of collapse. This stress-concentration would exacerbate tissue damage in the area surrounding the collapse [33] 
significantly, as would a rubber balloon, with high volumes or pressures [37, 38]. Others have shown heterogeneous changes in individual alveolar size and shape with lung inflation but also did not show balloon-like overexpansion [39]. The site of overdistension and potential rupture may be the alveolar duct, rather than the individual alveoli (Fig. 2a) [40]. Early work by Dreyfuss et al. demonstrated that high lung volume and airway pressure sufficient to cause over-distension, induced lung damage but did not cause injury as long as dynamic alveolar strain secondary to alveolar recruitment/ derecruitment (R/D) was prevented with adequate PEEP [41]. Similarly, Seah et al. showed that over-distension caused by high Vt did not cause lung histopathology unless it was combined with high dynamic strain when PEEP is set at zero [42, 43]. Using a novel method of polarized gas inhalation, which can identify the dynamic change in structures as small as alveoli and alveolar ducts, it was shown that increasing lung volume with PEEP actually decreased alveolar size, while increasing alveolar number [44]. Thus, the 'hyper-inflated' lung tissue seen on CT might not be caused by over-distended alveoli but rather by an increase in the number of smaller, newly recruited alveoli. In summary, the role of gross alveolar over-distension (i.e., balloonlike overexpansion) as the primary mechanism of VILI is still in question with many studies demonstrating that dynamic alveolar strain (i.e., R/D) and not OD is the primary mechanism of VILI $[45,46]$. These studies are further supported in the clinically meta-analysis by Amato, which demonstrated ARDS outcome was associated with driving pressure or dynamic tidal $\mathrm{R} / \mathrm{D}$ rather than static end inspiratory tidal volume/distension at given plateau pressure [22].

\section{Alveolar recruitment/derecruitment (R/D)}

The ability to adjust mechanical ventilator settings necessary to stabilize the lung during expiration is seen as a crucial method of reducing R/D and thus lung damage. Most studies have shown that a high static airway pressure (OD) with minimal dynamic strain (i.e., alveolar collapse and reopening) will not cause VILI [41, 42, 47, 48]. Direct measurement of alveolar R/D using in vivo microscopy demonstrated that stabilizing alveoli with adequate PEEP significantly reduced ALI [49]. The pathologic role of R/D was best evidenced in studies in which animals were ventilated at a high peak lung volume (high static strain) associated with lung over-distension with and without high dynamic strain (R/D). High static strain did not cause the histopathology and pulmonary edema characteristic of ARDS unless combined with high dynamic strain. Increasing Vt and reducing PEEP were used to cause high dynamic strain (Fig. 2b), while reducing Vt and increasing PEEP were used to cause low dynamic strain [47, 48]. Combined, these studies further demonstrate that dynamic strain caused by alveolar R/D, and not alveolar over-distension as was originally thought, is the main mechanism of VILI, which drives progressive ALI. Thus, if alveolar collapse during expiration can be prevented with properly adjusted PEEP, VILI should be dramatically reduced.

\section{Alveolar stress concentrators (SC)}

Recent work has identified another VILI mechanism, which occurs during heterogeneous ventilation when open alveoli are adjacent to collapsed or edema filled alveoli, which sets up stress-concentrators generating excessive strain across alveolar walls (Fig. 2c) [33, 34]. Retamal et al. demonstrated, in a novel heterogeneous rat lung injury model, 
that injurious stresses occur at the interface between collapsed and expanded [34]. They hypothesized that a local non-lobar atelectasis would act as a SC significantly exacerbating tissue damage in these areas. Their data supported this hypothesis, demonstrating increased inflammation and structural injury in the healthy tissue that was adjacent to the collapsed tissue during mechanical ventilation [34]. Cressoni et al. hypothesized that the mechanism of VILI in lungs with ALI was due to the presence of local inhomogeneities acting as SC [33]. The presence of local inhomogeneities was identified using $\mathrm{CT}$ in patients with ARDS. Increased lung inhomogeneity was correlated with the severity of ARDS and was the only variable independently associated with mortality. Increasing PEEP reduced lung inhomogeneity. Borges et al. showed increased inflammation in the lung tissue associated with lung inhomogeneities using combined positron emission tomography (PET) and CT, further supporting these studies [50]. Wellman et al. further supported the work of Borges and demonstrated that regional tidal lung strain causes local inflammation during mechanical ventilation in a sheep ARDS model [51].

The pathogenesis of ARDS can start when loss of surfactant function, caused by ventilation (either spontaneous or mechanical ventilation), leads to collapsed alveoli that act as SC in the tissue surrounding them $[52,53]$. Thus, SC may be the first step in ALI pathogenesis that if unchecked will result in ARDS. It has been shown that VILI can result even with low Vt ventilation $[54,55]$. It was hypothesized that the mechanism of low Vt-induced VILI was lung collapse secondary to the small ventilation volumes, resulting in heterogeneous alveolar ventilation causing $\mathrm{SC}$ and excessive local strain [56-58]. This hypothesis was supported by Wellman et al., who showed in early stages of ALI that: (1) high regional lung strain caused by SC may be present even when global strain is not in the pathologic range; (2) local inflammation has a positive linear relationship with tidal strain; (3) systemic inflammation (endotoxin infusion) exacerbates this inflammation; and (4) homogenizing regional tidal strain (reducing stress concentrators) by increasing PEEP and reducing Vt reduces local inflammation [51].

In summary, emerging data strongly suggests that the presence of SC is a major mechanism of VILI. The evidence also supports the hypothesis that dynamic strain caused by alveolar R/D significantly contributes to VILI pathophysiology, whereas high static strain (alveolar OD) is a less important VILI mechanism. Thus, this review will focus on how PEEP can be personalized using physiologic signals to reduce stress-concentrators (open the lung) and/or prevent dynamic strain (stabilize the lung).

\section{Methods and efficacy of personalizing PEEP Introduction}

Although the use of PEEP is the primary tool to stabilize the lung, decades of research have not discovered the optimal approach to set PEEP [59]. Multiple attempts have been made to personalize protective ventilation using changes in lung physiology. The current standard of care is a set Vt based on patient weight, while PEEP is personalized by a sliding scale based on changes in oxygenation [7]. The current methods and efficacy of personalizing PEEP to individual lung physiology used clinically will be reviewed. 


\section{Personalized PEEP overview}

Application of PEEP, before the onset of lung injury, has prevented the development of ALI in numerous animal studies [60]. This protection was effective in multiple injury models including high endothelial permeability, high vascular pressure, high surface tension, and high airway pressure [60]. Although multiple mechanisms, including alteration of the Starling fluid flux equation (i.e., increased interstitial pressure) [61] and preservation of surfactant function [52] played a role in PEEP-induced lung protection, stabilizing alveoli is critical and has been shown to block progressive ALI [49]. These studies suggest that properly adjusted PEEP may have a significant protective effect in patients with or at high-risk of developing ARDS. However, there is currently no consensus on the optimal method to set PEEP with the goal of reducing VILI and blocking progressive ALI [62].

Caramez et al. compared the use of multiple physiologic parameters to set PEEP following a recruitment maneuver (RM) in a sheep saline lavage model [24]. They found that dynamic tidal respiratory compliance, maximum $\mathrm{PaO}_{2}$, maximum $\mathrm{PaO}_{2}+\mathrm{PaCO}_{2}$, minimal shunt, lower inflection point $\left(P_{\text {FLEX }}\right)$, and the point of maximal compliance increase (Pmci,i) on the inflation limb of the pressure-volume (P-V) curve all set a similar level of PEEP. However, the PEEP obtained using the $P_{\text {FLEX }}$ on the deflation limb of the P-V curve and the maximal compliance decrease on the deflation limb set a significantly higher PEEP; the true inflection point on the inflation limb and minimum $\mathrm{PaCO}_{2}$ set a significantly lower PEEP. They concluded that open-lung PEEP (PEEP resulting in homogenous alveolar inflation) could be identified by a decremental PEEP trial following a RM using multiple physiologic parameters (maximum dynamic tidal respiratory compliance, maximum $\mathrm{PaO}_{2}$, maximum $\mathrm{PaO}_{2}+\mathrm{PaCO}_{2}$, minimum shunt or the inflation $P_{\text {FLEX }}$ and Pmci,i).

The current standard of care uses oxygenation as the criteria to set PEEP in combination with low Vt and Pplat $<30 \mathrm{cmH}_{2} \mathrm{O}$, but no difference in outcome was observed between high [63] and low PEEP [7] using this strategy. It has been shown that PEEP based on changes in oxygenation, not on changes in lung mechanics, may result in under treatment with end expiratory pressure insufficient to stabilize the lung [64]. Since oxygenation set PEEP is the current standard of care, we will begin by reviewing the evidence of efficacy for this strategy followed by other methods used to personalize PEEP that have a significant publication database for analysis.

\section{PEEP personalized by oxygenation}

Since the primary function of the lung is to oxygenate and ventilate, the first attempts to personalize PEEP used oxygenation to set the PEEP level. PEEP was increased with the focus on treating the blood gases until oxygenation was normalized, regardless of the impact on lung mechanics, which caused severe VILI with mortality rates between 50-75\% [65]. It has been shown that oxygenation does not identify the presence of alveolar R/D (i.e., dynamic strain) [8, 9], and improved oxygenation does not always identify lung recruitment [66]. Furthermore, PEEP set to optimize oxygenation has been shown to increase lung inflammation [67]. Although, as mentioned above, there are concerns that oxygenation is not the optimal physiologic parameter by which to set protective mechanical breath parameters, it remains the current clinical standard of care $[7,68]$. 
Chiumello et al. compared PEEP set using lung mechanics (stress index), esophageal pressure, and oxygenation and found that using oxygenation was the only method that provided PEEP levels that corresponded with lung recruitability and gradually increased with progressive lung injury [69]. This study was only designed to identify if PEEP maintained lung recruitment and thus we do not know if this strategy reduced mortality. Oxygenation may be beneficial as a physiologic feedback parameter, when used in conjunction with a RM, to identify the level of PEEP necessary to keep the newly recruited alveoli open. Borges et al. showed that following a RM, a combined $\mathrm{PaO}_{2}+\mathrm{PaCO}_{2}>400 \mathrm{mmHg}$ identified a fully inflated lung with minimal shunt (Fig. 3) [70]. There have been three large clinical trials studying the role of PEEP in ARDS: the ALVEOLI study [63] the LOV study [71], and the ExPress study [72]. Of the three, only the ALVEOLI study used oxygenation to set PEEP, the LOV and ExPress studies used open lung ventilation and lung mechanics, respectively. Although there was no outcome difference in any of these studies, the LOV and ExPress showed a survival benefit in severe ARDS patients when treated with higher PEEP [73].

In summary, a recent review suggests that mortality has not been reduced significantly in the past 15 years (1998-2013) [4] suggesting that using other physiologic parameters to adjust mechanical ventilator settings is necessary. Although using oxygenation to set PEEP can be useful, especially when combined with a RM, the lack of direct correlation between an open and stable lung and $\mathrm{PaO}_{2}$ renders this personalized PEEP strategy questionable. With that said, it has been shown in a secondary analysis of the LOV and ExPress studies that patients who improved oxygenation in response to PEEP had a lower risk of death [74].

\section{PEEP personalized by dead space}

Another physiologic parameter that has been used to optimize PEEP is Dead Space ventilation, often expressed as the dead space $\left(V_{\mathrm{D}}\right)$ to tidal volume $\left(V_{\mathrm{t}}\right)$ ratio $\left(V_{\mathrm{D}} / V \mathrm{t}\right)$.

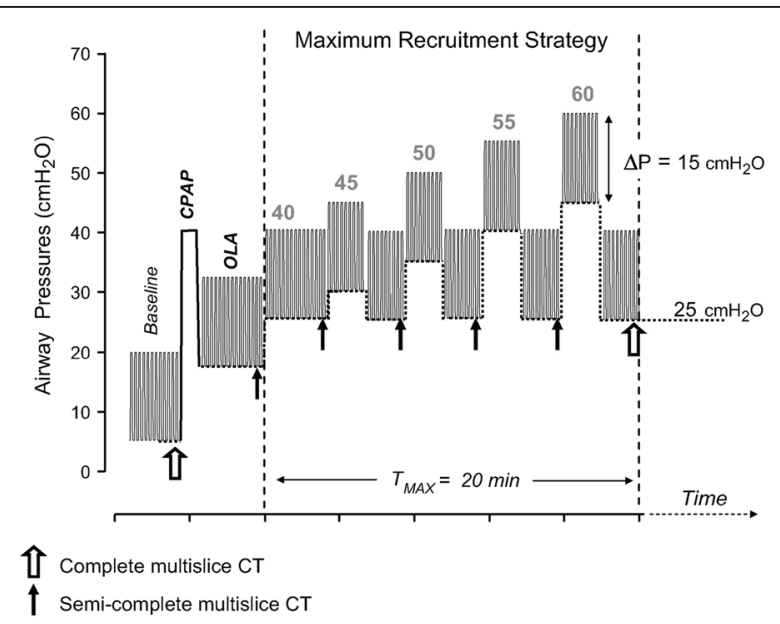

Fig. 3 Methods used to set PEEP using a combined recruitment maneuver, and PEEP titration to a $\mathrm{PO}_{2}+$ $\mathrm{PCO}_{2} \geq 400$. This protocol was conducted as computed tomography $(C T)$ was being performed to measure lung volume changes. PEEP was increased to $25 \mathrm{cmH}_{2} \mathrm{O}$ with a driving pressure $(\triangle \mathrm{P})$ of $15 \mathrm{cmH}_{2} \mathrm{O}$ above PEEP. If a $\mathrm{PO}_{2}+\mathrm{PCO}_{2} \geq 400$ was not obtained, PEEP was increased by $5 \mathrm{cmH}_{2} \mathrm{O}$ for $2 \mathrm{~min}$, returned to PEEP $25 \mathrm{cmH}_{2} \mathrm{O}$ for $2 \mathrm{~min}$ and repeated until $\mathrm{PO}_{2}+\mathrm{PCO}_{2} \geq 400$ or a PEEP of $45 \mathrm{cmH}_{2} \mathrm{O}$ was obtained. CPAP continuous positive airway pressure, OLA open lung approach [70] 
Elevated $V_{\mathrm{D}} / \mathrm{Vt}$ is a hallmark of ARDS and has been shown to be independently associated with increased mortality [75] and has also been shown to outperform any oxygenation index parameter in predicting ARDS mortality [76]. In a review by Suarez-Sipmann, it was shown that the recent advances in volumetric capnography (VCap) make it a powerful bedside tool to assess inadequate lung protective ventilator settings and detect lung over-distension (Fig. 4) [77]. Maisch et al. used a combination of highest compliance and lowest $V_{\mathrm{D}} / \mathrm{Vt}$ to set 'optimal' PEEP in anesthetized patients with healthy lungs [78]. They demonstrated that this combination resulted in the maximum number of effectively recruited alveoli, and that functional residual capacity (FRC) and $\mathrm{PaO}_{2}$ were both insensitive at detecting over-distension. This is supported by two physiologic studies using a porcine-ARDS model that showed $\mathrm{V}_{\mathrm{D}} / \mathrm{Vt}$ was useful for identifying lung collapse and the optimal PEEP necessary to maintain lung volume following a RM $[79,80]$. Although using VCap or $V_{\mathrm{D}} / \mathrm{Vt}$ to set PEEP has not been tested for efficacy in a clinical trial, it is a potentially useful tool to set PEEP at the bedside.

\section{PEEP personalized by imaging}

The goal of protective lung ventilation is to 'Open the Lung and Keep it Open' [81] and thus, imaging should be an excellent method to identify if this goal is achieved. Indeed, CT lung scans have taught us a tremendous amount about the impact of the mechanical breath on the heterogeneous changes in lung volume during ALI [82-85]. The problem is that CT is not a tool that can be used at the bedside and thus is unavailable for treatment of most ARDS patients. However, a novel bedside device recently developed, electrical impedance tomography (EIT), allows breath-to-breath measurement of lung ventilation at the bedside. Blandkman et al. recently demonstrated that EIT and the Bohr and Enghoff calculated dead space, both identified optimal PEEP, defined as equal distribution of inspired gas volume [86]. Interestingly, they also demonstrated that $V_{\mathrm{D}} / \mathrm{Vt}$ and the normalized Slope III (SnIII) of the end tidal

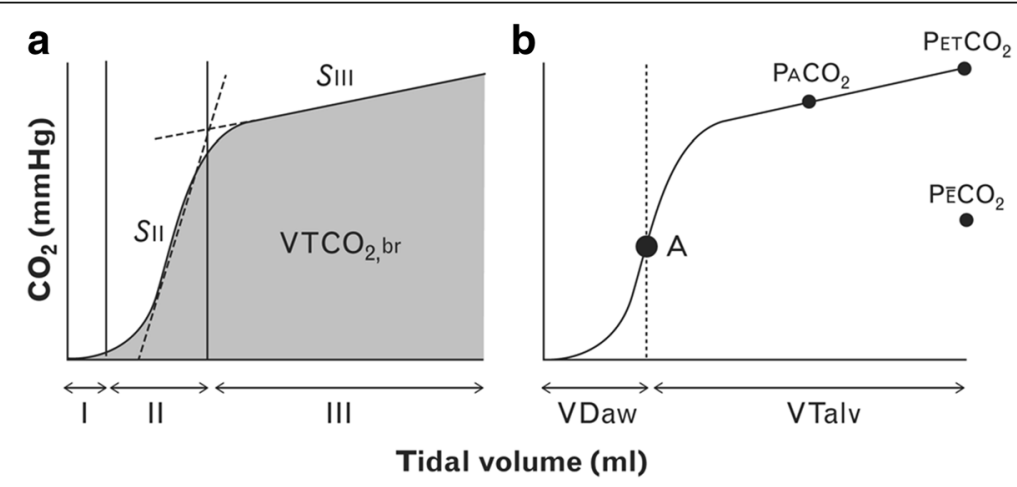

Fig. 4 Components of volumetric capnography that can be used to personalize PEEP. a The three phases of capnography are: phase I contains $\mathrm{CO}_{2}$-free gas from the previous tidal breath; phase II $\left(\mathrm{S}_{\|}\right)$is the steep slope contains $\mathrm{CO}_{2}$ from the alveolar compartment and mixed with $\mathrm{CO}_{2}$ in the airways from the previous breath; and phase III $\left(\mathrm{S}_{\mathrm{III}}\right)$ is entirely $\mathrm{CO}_{2}$ from alveoli and identifies the different time constants of $\mathrm{CO}_{2}$ being released from the capillaries and moved out of the alveoli. $\mathrm{VTCO}_{2}$, br is the volume of $\mathrm{CO}_{2}$ removed in one breath (grey shaded area). $\mathbf{b}$ The black dot (A) identifies the midpoint of $\mathrm{S}_{\|}$which identifies the mean airway-alveolar interface from both diffusive and convective transports. To the left of (A) represents airway dead space $\left(V_{\text {Daw }}\right)$ and to the right of $(\mathrm{A})$ represents alveolar tidal volume $\left(\mathrm{V}_{\text {Talv }}\right) . \mathrm{PaCO}_{2}=$ alveolar $\mathrm{CO}_{2}$; $\mathrm{PETCO}_{2}=$ end-tidal $\mathrm{CO}_{2} ; \mathrm{PECO}_{2}=$ mixed-expired $\mathrm{CO}_{2}$ [77] 
$\mathrm{CO}_{2}$ curve (Fig. 4) did not identify lung inhomogeneity. However, EIT can be used to identify the impact of PEEP on distribution of ventilation (Fig. 5) [87]. Although the majority of studies to date have simply been EIT validation experiments, a few have investigated the efficacy of EIT-guided PEEP. Muders et al., in a porcine oleic acid and abdominal hypertension-induced ARDS model, showed that EIT was effective at quantifying the amount of alveolar R/D at different PEEP levels [13]. They concluded that EIT has the ability to identify dynamic changes in tidal recruitment and thus may be an effective tool to titrate optimal PEEP. These findings were supported by Liu et al. who demonstrated that EIT can identify lung overinflation and R/D at various levels of PEEP in a porcine saline lavage-induced ARDS model [88]. Finally, Gerhard et al. compared PEEP set to ARDSnet guidelines [7] with PEEP set by EIT-derived compliance to maximize PEEP-induced lung recruitment in a porcine saline lavage ARDS model [89]. They demonstrated that EIT-guided ventilation resulted in a higher PEEP, improved global and regional compliance, improved oxygenation, and reduced lung histopathology as compared with ARDSnet protocol set PEEP. Combined data suggest that EIT may become an important tool in setting optimal PEEP.

\section{PEEP personalized by lung mechanics: compliance/elastance}

Retrospective analysis of the ARMA data [68] demonstrated that lung mechanics, in the form of changes in compliance, are much more predictive of mortality than $\mathrm{Vt}$ [90]. Although these data are very interesting, it must be remembered that the ARMA trial was not designed to study lung mechanics and patient contribution to respiration was not identified, which may confound these interpretation of these results. The use of compliance to adjust PEEP is not a new concept. Indeed, Suter et al. first described the use of compliance adjusted PEEP over 40 years ago (Fig. 6) [91]. This early work has been supported by Chiew et al. who investigated a patient-specific, model-based, PEEP optimization strategy analyzing the relationship between the constant lung elastance $\left(E_{\text {lung }}\right)$ and the time-variant dynamic elastance $\left(E_{\text {drs }}\right)$ in ARDS patients [92]. They found that PEEP set using the model-based changes in elastance was superior to that of clinically set PEEP in maximizing lung recruitment and minimizing the work of

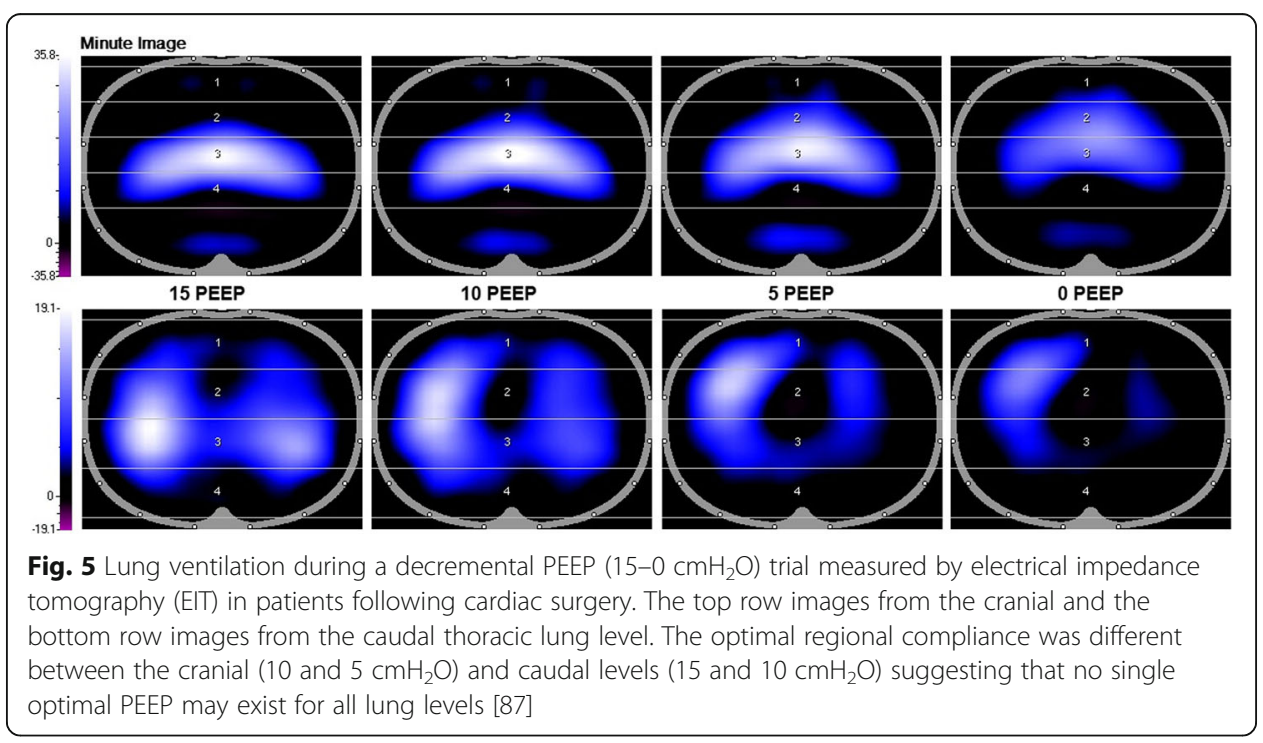




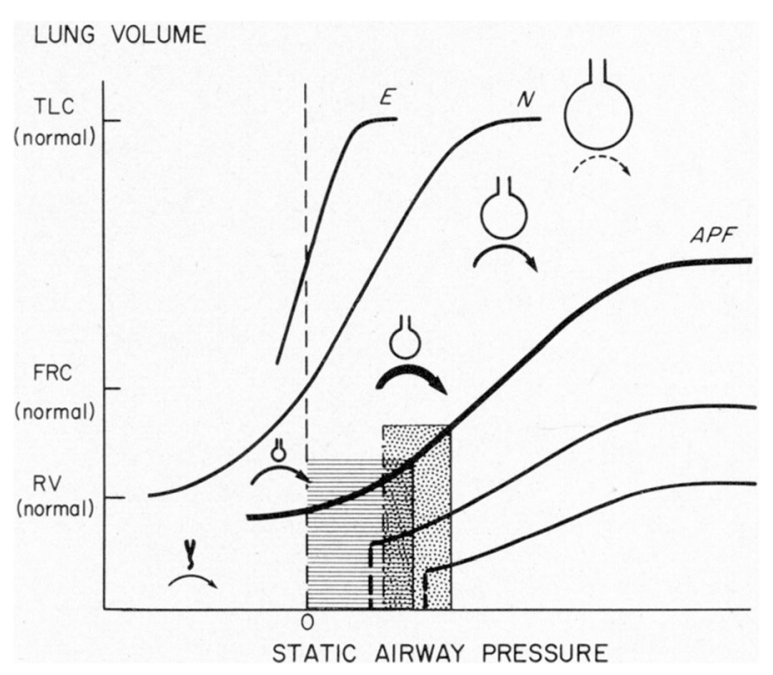

Fig. 6 Use of the pressure/volume (P/V curve to personalize PEEP. The shape of the P/V curve changes from normal $(N)$ and differs greatly with emphysema ( $E$ ) or acute pulmonary failure (APF). The $P / V$ relationship during tidal ventilation is depicted in the shaded area with and without PEEP. $R V$ regional volume at which alveoli collapse, FRC functional residual capacity, and TLC total lung capacity. Central drawing of alveoli size changes along the $P / V$ curve [91]

breathing. Continuous monitoring of dynamic compliance $\left(C_{\mathrm{dyn}}\right)$ as a tool to personalize PEEP was studied by Suarez-Sipmann et al. in a porcine saline lavage-induced ARDS model [93]. They compared changes in $C_{\mathrm{dyn}}$, oxygenation, and lung inflation, measured by CT following a RM plus PEEP titration trial. Initially, there was an increase in $C_{\mathrm{dyn}}$ with each reduced PEEP level. The beginning of lung collapse was defined as the PEEP level at which $C_{\mathrm{dyn}}$ began to fall. The PEEP value selected by $C_{\mathrm{dyn}}$ was compared with that selected by oxygenation and CT measurements. Both oxygenation and CT confirmed that the PEEP set by $C_{\mathrm{dyn}}$ maintained a fully open lung and concluded that $C_{\mathrm{dyn}}$ might be a valuable bedside tool to set optimal PEEP. The use of lung compliance to identify the optimally protective mechanical breath has recently been reassessed in a retrospective paper analyzing the parameters associated with increased mortality. In this statistical analysis by Amato et al., 3562 patients enrolled in nine previous ARDSnet studies were studied, and it was shown that higher plateau pressure (Pplat) was not always associated with increased mortality nor was higher PEEP always protective, whereas driving pressure $(\Delta \mathrm{P}=$ tidal volume/respiratory-system compliance) was strongly associated with survival [22]. This study reaffirms the importance of lung compliance in identifying the optimally protective mechanical breath.

\section{Pressure/volume curve}

Evidence supporting the clinical use of the whole lung pressure volume $(\mathrm{P} / \mathrm{V})$ curve as a tool to identify optimal PEEP was demonstrated by Amato et al. in two clinical trials [94, 95]. Using the P/V curve to set PEEP requires a maneuver which slowly inflates the lung, with the goal being to identify the upper and lower infection points $\left(P_{\text {FLEX }}\right)$ on this $\mathrm{P} / \mathrm{V}$ curve (Fig. 7$)$. The lower $P_{\mathrm{FLEX}}$ is postulated to identify the pressure at the beginning of alveolar recruitment and the upper $P_{\mathrm{FLEX}}$ is at the point of lung over-distension. They showed that a Vt of $6 \mathrm{cc} / \mathrm{kg}$ with PEEP set above the lower $P_{\text {FLEX }}$ improved 28-day survival as compared with a ventilation strategy using a 


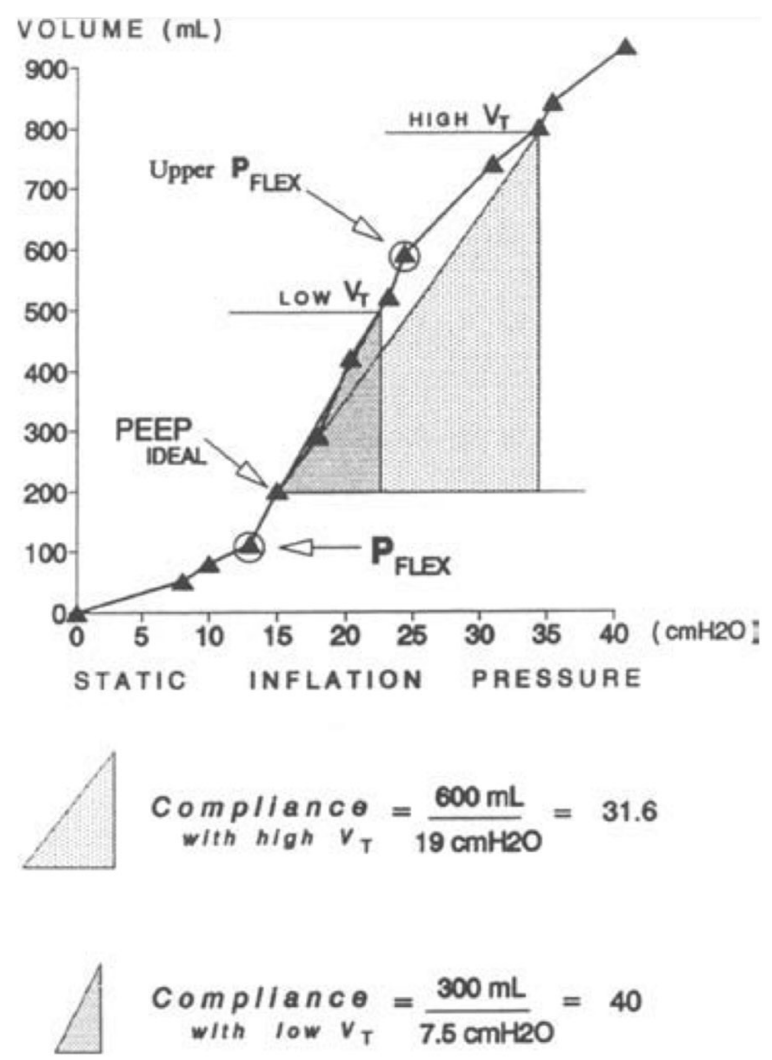

Fig. 7 Pressure/volume (P/M curve from an ARDS patient showing both the lower and upper inflection points $\left(P_{\mathrm{FLEX}}\right)$. The hypothesis is that the lower $P_{\mathrm{FLEX}}$ is the critical alveolar opening point and the upper $P_{\mathrm{FLEX}}$ the point at which alveoli begin to over-distend, however, this hypothesis has been challenged [97, 98]. In this patient, ventilation with a high tidal volume $\left(\mathrm{Vt}=10 \mathrm{ml} / \mathrm{kg}\right.$ plus PEEPIDEAL $\left.=15 \mathrm{cmH}_{2} \mathrm{O}\right)$ would cause over-distension since ventilation is well above the upper $P_{\text {FLEX }}$. Ventilation with low Vt and PEEPIDEAL was below the upper $P_{\text {FLEX. }}$ The calculated lung compliance was increased from 31.6 to 40 with low Vt ventilation [94]

Vt of $12 \mathrm{cc} / \mathrm{kg}$ combined with lowest set PEEP to maintain acceptable oxygenation [95]. However, subsequent studies demonstrated that alveoli recruit continually throughout the entire inflation curve in both animal models $[96,97]$ and in humans. In addition, it was shown that there was a higher amount of aerated lung tissue above the point of maximum curvature on the deflation curve [98] and a higher number of alveoli above the upper $P_{\text {FLEX }}$ on the deflation curve [97] as compared with the lower $P_{\text {FLEX }}$ on the inflation curve. These studies suggest that using the deflation limb of the P/V curve to set PEEP may be superior, in terms of the amount of recruited lung, as compared to the inflation limb. Although using the $\mathrm{P} / \mathrm{V}$ curve as a physiologic tool to personalize PEEP can be effective, generating the $\mathrm{P} / \mathrm{V}$ curve is a complex procedure and there is a risk of causing hemodynamic compromise and injuring the lung during the inflation procedure. Also, ALI is always evolving and thus even if the PEEP is set properly using the $\mathrm{P} / \mathrm{V}$ curve, it must be reset as the lung improves or deteriorates in function.

\section{Transpulmonary pressure}

Patients at risk of developing ARDS often have a decrease in chest wall compliance secondary to fluid overload and/or increased intra-abdominal pressure. Therefore, it is 
possible that PEEP could be set too low unless the transpulmonary pressure (Ptp) is known. Clinically, esophageal pressure (Pes) is used as a surrogate for pleural pressure (Ppl) and used to calculate Ptp. It has shown that PEEP set to maintain Ptp above $0 \mathrm{cmH}_{2} \mathrm{O}$ had positive impact in both animal $[99,100]$ and human $[101,102]$ studies. Personalizing PEEP using Ptp is a physiologically sound concept since Ptp is the force that distends the lung. However, Pes is not the perfect surrogate of Ppl and thus the calculated Ptp might not be accurate. In a recent study, Huang et al. compared open-lung PEEP guided by CT to Ptp guided PEEP (i.e., PEEP set to always keep end Ptp above $0 \mathrm{cmH}_{2} \mathrm{O}$ ) in a porcine saline lavage lung injury model [103]. They found that Ptp-guided PEEP was unable to maintain recruited lung open with a hypothesized mechanism for this failure being an increase in the superimposed pressure between the esophageal plane and dorsal lung level. However, using Ptp to guide PEEP is a physiologically sound technique and, there is a multicenter randomized clinical trial using Ptp-guided ventilation that should help determine the efficacy of this ventilation strategy [104].

\section{Stress index}

In 2000, Ranieri et al. demonstrated that the pressure-time (P-t) curve generated using constant flow ventilation could be used to identify protective mechanical ventilation (Fig. 8) [105]. They used the shape of the curve to identify the stress being directed into the lung during mechanical ventilation. These studies demonstrated that if the P-t curve was straight there was minimal stress, whereas, if the curve had a downward concavity, there was increasing compliance, and if there is an upward concavity, there is decreasing compliance. The term $b$ in the curve-fitting equation (Fig. 8) describes the shape of the P-t curve, and they found that a coefficient $b$ of 1.00 was associated with lung protection, determined by reduced histopathology and inflammatory mediators. An extension of this work showed that a coefficient of $b<1$ correlated with tidal recruitment,

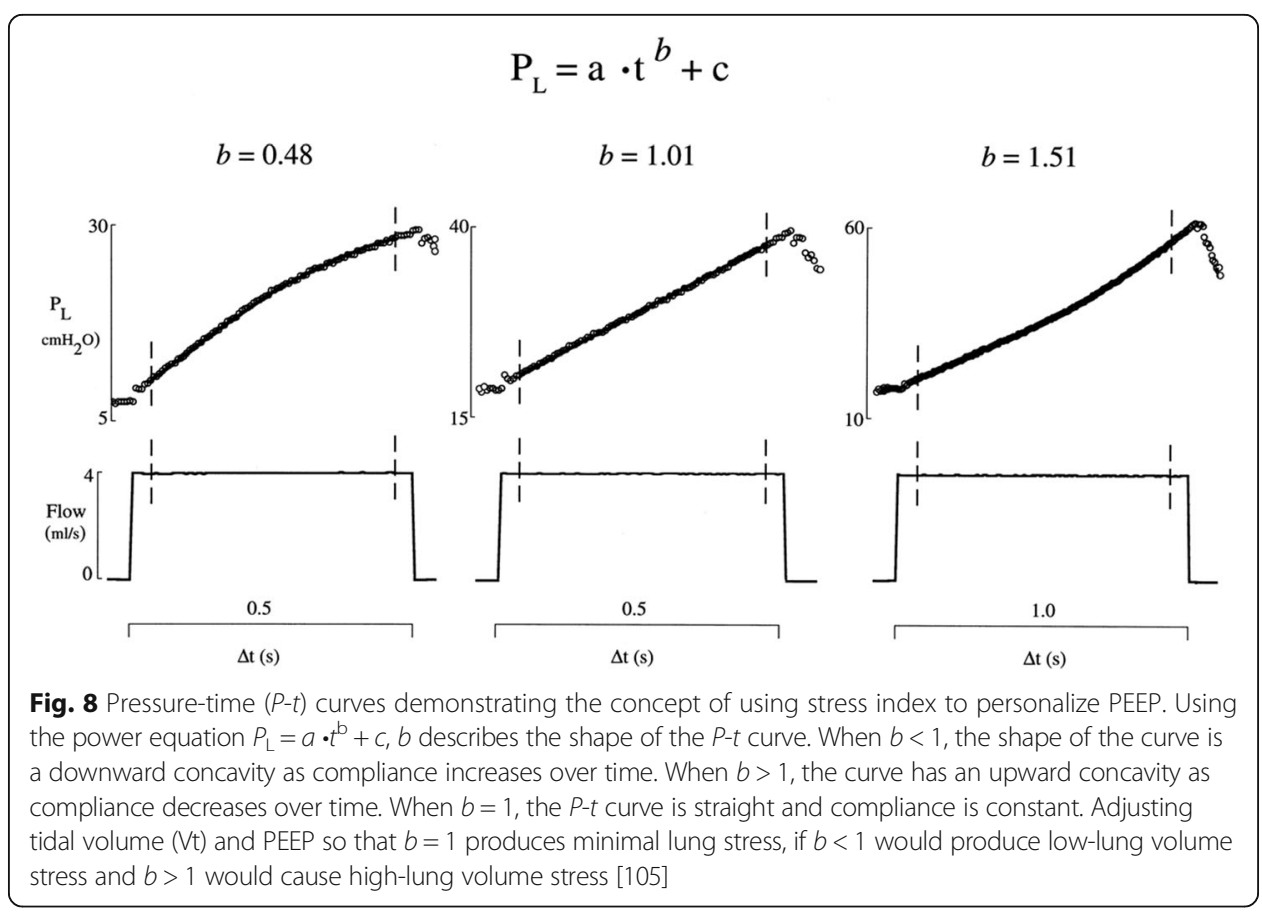


and a $b>1$ correlated with hyperinflation, with $b=1$ correlating with non-injurious mechanical ventilation, confirming the predictive power of this stress-index to identify injurious mechanical ventilation [26]. The accuracy of the stress-index to identify injurious mechanical ventilator settings likely to cause VILI was recently confirmed in humans [106]. CT was used to identify morphological markers of VILI including tidal hyperinflation, hyperinflated lung at expiration, and tidal recruitment. Results demonstrated that the Pplat currently considered not to cause VILI $\left(\leq 30 \mathrm{cmH}_{2} \mathrm{O}\right)$ was shown to cause tidal hyperinflation, whereas stress-index suggested a Pplat of $<25 \mathrm{cmH}_{2} \mathrm{O}(b<1.05)$ would not and was confirmed by CT. Stress-index was also superior to Pplat at identifying the optimally protective ventilator settings in the presence of decreased chest wall compliance. Grasso et al. [107] demonstrated in ARDS patients that using stress-index to set PEEP reduced alveolar hyperinflation as compared to PEEP set using standard of care [7], although these findings have been challenged [108]. Although use of stress index to set PEEP has several physiologic advantages over using oxygenation, which is the standard of care, and there is a commercially available ventilator that can measure stress index, this technique has not been shown conclusively superior to the current strategy of adjusting PEEP using oxygenation.

\section{Time controlled PEEP}

A novel physiologic tool to set PEEP is the slope of the expiratory flow curve $\left(\mathrm{Sl}_{\mathrm{EFC}}\right)$ in conjunction with airway pressure release ventilation (APRV) (Fig. 9) [109, 110]. Although this method is not widely utilized throughout the country, it is intensely used in some hospitals and can be used as a primary mode of ventilation [109]. This time-controlled PEEP is not directly set but rather the time during expiration $\left(T_{\mathrm{LOW}}\right)$ is sufficiently brief to prevent the lung from fully emptying. Thus, both lung volume and pressure (i.e., PEEP) remain at the beginning of lung reinflated. The shorter the duration of expiration, the higher the retained-end expiratory lung volume and positive-end release pressure (PERP) that remains in the lung.

It is important to understand that the personalized APRV (P-APRV) used to set time-controlled PEEP $[109,110]$ and inverse inspiratory:expiratory (I:E) ratio are not at all the same mechanical breath. Although there are many differences between P-APRV and inverse I:E, I will focus on the large difference in the time at expiration between these two ventilation strategies. It was shown by Neumann et al. that the ARDS lung collapses very rapidly, their data showing collapse in $0.6 \mathrm{~s}$ after the initiation of expiration [17]. Our work using direct observation of alveoli during mechanical ventilation has also shown a very rapid alveolar collapse in the ARDS lung [40, 111-113]. Unlike APRV, inverse ratio ventilation does not allow direct and independent adjustments of the expiratory and inspiratory times. Thus, if the expiratory duration with inverse I:E is not less than 0.4-0.6 s, which is most often the case, alveoli would have sufficient time to collapse with each breath and inverse I:E would not be defined as time controlled PEEP, since the lung was allowed time to empty.

An example of how the $\mathrm{Sl}_{\mathrm{EFC}}$ will change with progressive ALI and how we can use the $\mathrm{Sl}_{\mathrm{EFC}}$ to set the expiratory duration necessary to stabilize the lung is as follows: a hypothetical normal lung has been given a $\mathrm{Sl}_{\mathrm{EFC}}$ of $\sim 45^{\circ}$ and an ARDS lung a $\mathrm{Sl}_{\mathrm{EFC}}$ of $\sim 30^{\circ}$ (Fig. 9b). To set the optimal expiratory duration necessary to stabilize the lung, 


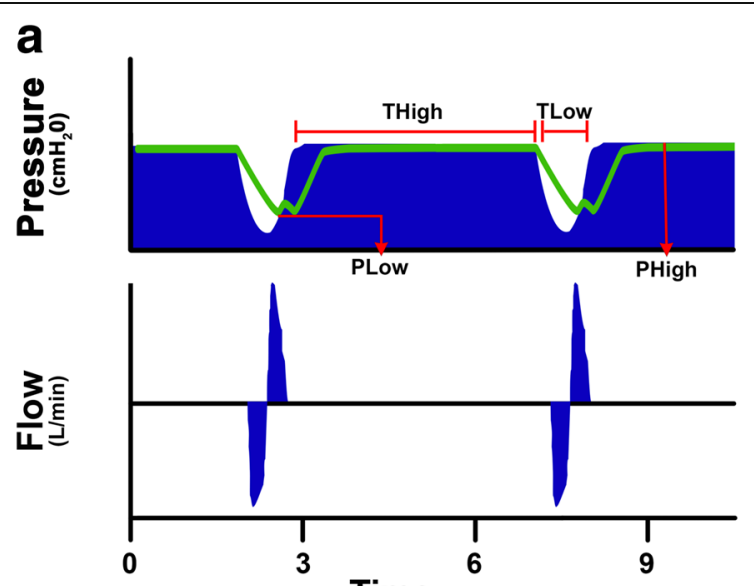

Time (sec)

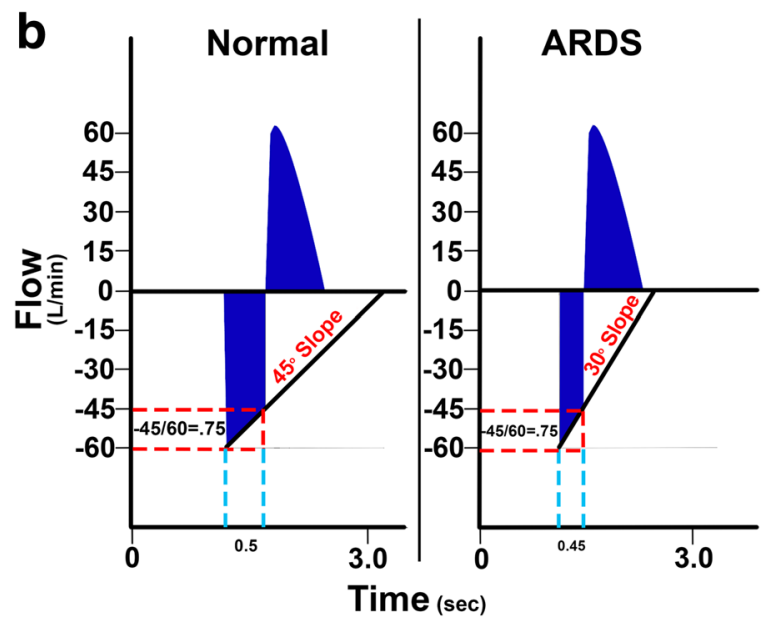

Fig. 9 a Typical airway pressure release ventilation (APRV) airway pressure and flow curves. Correctly set APRV has a very brief duration at expiration (time at low pressure, $T_{\text {Low }}$ ) and extended inspiratory duration (time at high pressure, $T_{\text {High }}$ ) [109]. The $T_{\text {High }}$ is $~ 90 \%$ of each breath. The two other ARPV settings are the pressure at inspiration $\left(P_{\text {High }}\right)$ and at expiration $\left(P_{\text {Low }}\right)$. $P_{\text {High }}$ is set sufficiently high to recruit and open alveoli and $P_{\text {Low }}$ is always set at $0 \mathrm{cmH}_{2} \mathrm{O}$ to facilitate expiratory flow. However, $T_{\text {Low }}$ is sufficiently short such that end-expiratory pressure $\left(P_{\text {Low }}\right)$ never reaches $0 \mathrm{cmH}_{2} \mathrm{O}$ identified by the tracheal pressure (green line) maintaining a level of PEEP. $\mathbf{b}$ This figure summarizes our novel method to maintain alveolar stability by adaptively adjusting the expiratory duration as directed by the expiratory flow curve. The rate of lung collapse is seen in the normal (slope $45^{\circ}$ ) and acutely injured lung (ARDS, slope $30^{\circ}$ ). ARDS causes a more rapid lung collapse due to decreased lung compliance. Our preliminary studies have shown that if the ratio of the peak expiratory flow (PEF, $-60 \mathrm{~L} / \mathrm{min})$ to when we end expiratory flow $(E E F,-45 \mathrm{~L} / \mathrm{min})$ (EEF/ $\mathrm{PEF}$ ) is equal to $75 \%$ that this expiratory duration $(0.5 \mathrm{~s})$ is sufficient to stabilize alveoli $[40,111]$. The lung with ARDS collapses more rapidly such that the EEF/PEF-75\% identifies an expiratory duration of $0.45 \mathrm{~s}$ necessary to stabilize alveoli. Although the EEF/PEF is fixed, the expiratory duration is not, but rather adaptive and will stabilize alveoli regardless of lung injury severity. Thus, this method of setting expiratory duration is adaptive to changes in lung pathophysiology and personalizes the mechanical breath to each individual patient

the end expiratory flow to peak expiratory flow ratio (EEF/PEF) is used. It has been shown that the ratio that best stabilizes the lung but is still able to adequately ventilate the patient or animal is $75 \%[40,111,113,114]$. In the example, the PEF is $-60 \mathrm{~L} / \mathrm{min}$ so to determine when to stop expiration take $-60 \times 0.75=45 \mathrm{~L} / \mathrm{min}$, and thus the clinician would terminate exhalation and reapply the continuous positive airway pressure (CPAP) at $-45 \mathrm{~L} / \mathrm{min}$. In the normal lung, the expiratory duration would be $0.5 \mathrm{~s}$ (Fig. 9b). With the development of ALI or ARDS, the lung becomes noncompliant 
and collapses very rapidly decreasing the $\mathrm{Sl}_{\mathrm{EFC}}$ to $\sim 30^{\circ}$. Using the same equation used in the normal lung, but with a steeper slope, we see that the expiratory time has been reduced from 0.5 to $0.45 \mathrm{~s}$ in order to prevent alveolar collapse in this noncompliant lung (Fig. 9b). This method results in a time-controlled PEEP, effectively minimizing dynamic strain (Fig. 9b) by stabilizing alveoli that uses two mechanisms: time and pressure [110].

Multiple studies have shown that this combined method of PEEP plus a brief release time is very effective at stabilizing alveoli and alveolar ducts, reducing tissue strain $[40,111]$, blocking progressive ALI, and reducing ARDS incidence in a clinically applicable, high-fidelity, porcine model of sepsis and gut ischemia/reperfusion-induced ARDS [113], and in a trauma patient statistical analysis [114]. More clinical studies are necessary to confirm the efficacy of this novel method to stabilize the lung.

\section{Conclusions}

It is clear that a high level of dynamic strain caused by alveolar R/D is a major mechanism of lung tissue damage associated with VILI. Application of PEEP is currently the primary strategy by which to minimize dynamic strain for established ARDS. In addition, early PEEP application has been effective at reducing the complication associated with mechanical ventilation in both animal and human studies. It is also clear that in order for PEEP to be effective, it must be personalized to the specific pathology of each patient's lung. The continued high mortality rate of ARDS supports the hypothesis that the current PEEP strategies are not always effective [1]. Multiple methods to personalize PEEP have been tested and have been shown to be capable of stabilizing the lung. A large body of literature supports the use of RMs to open the lung, prior to the application of PEEP, which is set based on physiologic feedback. Recent clinical studies are attempting to personalize PEEP following RMs in humans $[67,115]$. The main problem with the use of RMs is that they cannot be given very often, due to potential serious side effects, and the acutely injured lung is constantly changing. Thus, if lung pathology increases following the initial PEEP setting, lung instability would go unrecognized, causing additional VILI-induced lung damage. A novel method of personalizing PEEP is the using of expiratory flow curve during APRV. The advantage is that a RM is not required so that adjustments in expiratory duration are adaptive with progressive changes in acute lung injury, regardless if these changes are for the better or worse. Also, this method does not directly set PEEP but rather uses a short expiratory duration to generate intrinsic PEEP, which is used as a tool to stabilize the lung. Both animal studies and a human statistical analysis suggest that adjusting the release time on a breath-to-breath basis may be the optimal mechanism to adaptively personalize PEEP.

\footnotetext{
Abbreviations

ALI: Acute lung injury; APRV: Airway pressure release ventilation; ARDS: Acute respiratory distress syndrome; CPAP: Continuous positive airway pressure; CT: Computed tomography; EEF/PEF: End expiratory flow to peak expiratory flow ratio; EIT: Electrical impedance tomography; FRC: Functional residual capacity; OD: Over-distension; P/ V: Pressure/volume; P-APRV: Personalized airway pressure release ventilation; PEEP: Positive-end expiratory pressure; Pes: Esophageal pressure; $P_{\mathrm{FLEx}}$ : Lower inflection point; Pmci,l: Maximal compliance increase; Ppl: Pleural pressure; Ptp: Transpulmonary pressure; R/D: Recruitment and derecruitment; RACE: Rapid alveolar collapse and expansion; RM: Recruitment maneuver; S-C: Stress concentration; SC: Stress concentrators; SI EFC: Slope of the expiratory flow curve; VCap: Volumetric capnography; VILI: Ventilator-induced lung injury; Vt: Tidal volume
} 


\section{Funding}

Salary support for JS is from NIH R01 HL131143.

\section{Authors' contributions}

GFN drafted the manuscript. PLA, NMH, JS, and LAG critically revised the manuscript. GFN and LAG helped to conceive the manuscript. All authors read and approved the final manuscript.

\section{Competing interests}

PLA, GFN, and NMH have presented and received honoraria and/or travel reimbursement at event(s) sponsored by Dräger Medical Systems, Inc., outside of the published work. PLA, GFN, NMH, and LAG have lectured for Intensive Care Online Network, Inc. (ICON). NMH is the founder of ICON, of which PLA is an employee. NMH holds patents on a method of initiating, managing, and/or weaning airway pressure release ventilation, as well as, controlling a ventilator in accordance with the same, but these patents are not commercialized, licensed nor royalty-producing. The authors maintain that industry had no role in the design and conduct of the study; the collection, management, analysis, or interpretation of the data; nor the preparation, review, or approval of the manuscript.

\section{Author details}

${ }^{1}$ Department of Surgery, SUNY Upstate Medical University, Syracuse, NY, USA. ${ }^{2}$ Intensive Care Online (ICON), Baltimore, MD, USA. ${ }^{3}$ Department of Trauma Critical Care Medicine, R Adams Cowley Shock Trauma Center, University of Maryland, Baltimore, MD, USA. ${ }^{4}$ Biological Sciences Department, Biological Sciences Department, SUNY Cortland, Cortland, NY, USA. ${ }^{5}$ Cardiopulmonary Critical Care Lab, Department of Surgery, Upstate Medical University, 750 East Adams Street, Syracuse, NY 13210, USA.

Received: 7 October 2016 Accepted: 26 January 2017

Published online: 02 February 2017

\section{References}

1. Villar J, Blanco J, Kacmarek RM (2016) Current incidence and outcome of the acute respiratory distress syndrome. Curr Opin Crit Care 22:1-6

2. Force ADT, Ranieri VM, Rubenfeld GD, Thompson BT, Ferguson ND, Caldwell E, Fan E, Camporota L, Slutsky AS (2012) Acute respiratory distress syndrome: the Berlin definition. JAMA 307:2526-2533

3. Guerin C, Reignier J, Richard JC (2013) Prone positioning in the acute respiratory distress syndrome. N Engl J Med 369:980-981

4. Villar J, Sulemanji D, Kacmarek RM (2014) The acute respiratory distress syndrome: incidence and mortality, has it changed? Curr Opin Crit Care 20:3-9

5. Neto AS, Simonis FD, Barbas CS, Biehl M, Determann RM, Elmer J, Friedman G, Gajic O, Goldstein JN, Linko R, Pinheiro de Oliveira R, Sundar S, Talmor D, Wolthuis EK, Gama de Abreu M, Pelosi P, Schultz MJ, Investigators PRVN (2015) Lung-protective ventilation with low tidal volumes and the occurrence of pulmonary complications in patients without acute respiratory distress syndrome: a systematic review and individual patient data analysis. Crit Care Med 43:2155-2163

6. Gong MN, Thompson BT (2016) Acute respiratory distress syndrome: shifting the emphasis from treatment to prevention. Curr Opin Crit Care 22:21-37

7. ARDSnet (2000) Ventilation with lower tidal volumes as compared with traditional tidal volumes for acute lung injury and the acute respiratory distress syndrome. The Acute Respiratory Distress Syndrome Network. N Engl J Med 342:1301-1308

8. Andrews P, Sadowitz B, M. K-S, Satalin J, Roy S, Snyder K, Gatto L, Nieman G, Habashi N, (2015) Alveolar instability (atelectrauma) is not identified by arterial oxygenation predisposing the development of an occult ventilatorinduced lung injury. Intensive Care Med Exp 3:1-12

9. Baumgardner JE, Markstaller K, Pfeiffer B, Doebrich M, Otto CM (2002) Effects of respiratory rate, plateau pressure, and positive end-expiratory pressure on PaO2 oscillations after saline lavage. Am J Respir Crit Care Med 166:1556-1562

10. Branson RD, Johannigman JA, Campbell RS, Davis K Jr (2002) Closed-loop mechanical ventilation. Respir Care 47: 427-451, discussion 451-423

11. Pomprapa A, Schwaiberger D, Pickerodt P, Tjarks O, Lachmann B, Leonhardt S (2014) Automatic protective ventilation using the ARDSNet protocol with the additional monitoring of electrical impedance tomography. Crit Care 18:R128

12. Boehme S, Bentley AH, Hartmann EK, Chang S, Erdoes G, Prinzing A, Hagmann M, Baumgardner JE, Ullrich R, Markstaller K, David M (2015) Influence of inspiration to expiration ratio on cyclic recruitment and derecruitment of atelectasis in a saline lavage model of acute respiratory distress syndrome. Crit Care Med 43:e65-74

13. Muders T, Luepschen H, Zinserling J, Greschus S, Fimmers R, Guenther U, Buchwald M, Grigutsch D, Leonhardt S, Putensen C, Wrigge H (2012) Tidal recruitment assessed by electrical impedance tomography and computed tomography in a porcine model of lung injury*. Crit Care Med 40:903-911

14. Albert SP, DiRocco J, Allen GB, Bates JH, Lafollette R, Kubiak BD, Fischer J, Maroney S, Nieman GF (2009) The role of time and pressure on alveolar recruitment. J Appl Physiol 106:757-765

15. Smith BJ, Grant KA, Bates JH (2013) Linking the development of ventilator-induced injury to mechanical function in the lung. Ann Biomed Eng 41:527-536

16. Henderson WR, Dominelli PB, Molgat-Seon Y, Lipson R, Griesdale DE, Sekhon M, Ayas N, Sheel AW (2016) Effect of tidal volume and positive end-expiratory pressure on expiratory time constants in experimental lung injury. Phys Rep 4:1-11

17. Neumann P, Berglund JE, Fernandez Mondejar E, Magnusson A, Hedenstierna G (1998) Dynamics of lung collapse and recruitment during prolonged breathing in porcine lung injury. J Appl Physiol 85:1533-1543

18. Smith BJ, Lundblad LK, Kollisch-Singule M, Satalin J, Nieman G, Habashi N, Bates JH (2015) Predicting the response of the injured lung to the mechanical breath profile. J Appl Physiol 118:932-940 
19. Schranz C, Becher T, Schadler D, Weiler N, Moller K (2014) Model-based setting of inspiratory pressure and respiratory rate in pressure-controlled ventilation. Physiol Meas 35:383-397

20. Ferrando C, Suarez-Sipmann F, Gutierrez A, Tusman G, Carbonell J, Garcia M, Piqueras L, Compan D, Flores S, Soro M, Llombart A, Belda FJ (2015) Adjusting tidal volume to stress index in an open lung condition optimizes ventilation and prevents overdistension in an experimental model of lung injury and reduced chest wall compliance. Crit Care 19:9

21. Protti A, Maraffi T, Milesi M, Votta E, Santini A, Pugni P, Andreis DT, Nicosia F, Zannin E, Gatti S, Vaira V, Ferrero S, Gattinoni L (2016) Role of Strain rate in the pathogenesis of ventilator-induced lung edema. Crit Care Med 44: e838-845

22. Amato MB, Meade MO, Slutsky AS, Brochard L, Costa EL, Schoenfeld DA, Stewart TE, Briel M, Talmor D, Mercat A, Richard JC, Carvalho CR, Brower RG (2015) Driving pressure and survival in the acute respiratory distress syndrome. N Engl J Med 372:747-755

23. Hess DR (2015) Recruitment Maneuvers and PEEP Titration. Respir Care 60:1688-1704

24. Caramez MP, Kacmarek RM, Helmy M, Miyoshi E, Malhotra A, Amato MB, Harris RS (2009) A comparison of methods to identify open-lung PEEP. Intensive Care Med 35:740-747

25. Hata JS, Togashi K, Kumar AB, Hodges LD, Kaiser EF, Tessmann PB, Faust CA, Sessler DI (2014) The effect of the pressure-volume curve for positive end-expiratory pressure titration on clinical outcomes in acute respiratory distress syndrome: a systematic review. J Intensive Care Med 29:348-356

26. Grasso S, Terragni P, Mascia L, Fanelli V, Quintel M, Herrmann P, Hedenstierna G, Slutsky AS, Ranieri VM (2004) Airway pressure-time curve profile (stress index) detects tidal recruitment/hyperinflation in experimental acute lung injury. Crit Care Med 32:1018-1027

27. Takeuchi M, Goddon S, Dolhnikoff M, Shimaoka M, Hess D, Amato MB, Kacmarek RM (2002) Set positive endexpiratory pressure during protective ventilation affects lung injury. Anesthesiology 97:682-692

28. Soroksky A, Esquinas A (2012) Goal-directed mechanical ventilation: are we aiming at the right goals? A proposal for an alternative approach aiming at optimal lung compliance, guided by esophageal pressure in acute respiratory failure. Crit Care Res Prac 2012:597932

29. Sundaresan A, Yuta T, Hann CE, Chase JG, Shaw GM (2009) A minimal model of lung mechanics and model-based markers for optimizing ventilator treatment in ARDS patients. Comput Methods Programs Biomed 95:166-180

30. Talmor D, Sarge T, O'Donnell CR, Ritz R, Malhotra A, Lisbon A, Loring SH (2006) Esophageal and transpulmonary pressures in acute respiratory failure. Crit Care Med 34:1389-1394

31. Hubmayr RD (2002) Perspective on lung injury and recruitment: a skeptical look at the opening and collapse story. Am J Respir Crit Care Med 165:1647-1653

32. Gattinoni L, Pesenti A (2005) The concept of "baby lung". Intensive Care Med 31:776-784

33. Cressoni M, Cadringher P, Chiurazzi C, Amini M, Gallazzi E, Marino A, Brioni M, Carlesso E, Chiumello D, Quintel M, Bugedo G, Gattinoni L (2014) Lung inhomogeneity in patients with acute respiratory distress syndrome. Am J Respir Crit Care Med 189:149-158

34. Retamal J, Bergamini BC, Carvalho AR, Bozza FA, Borzone G, Borges JB, Larsson A, Hedenstierna G, Bugedo G, Bruhn A (2014) Non-lobar atelectasis generates inflammation and structural alveolar injury in the surrounding healthy tissue during mechanical ventilation. Crit Care 18:505

35. Santos CC, Zhang H, Liu M, Slutsky AS (2005) Bench-to-bedside review: biotrauma and modulation of the innate immune response. Crit Care 9:280-286

36. Gattinoni L, Pesenti A, Avalli L, Rossi F, Bombino M (1987) Pressure-volume curve of total respiratory system in acute respiratory failure. Computed tomographic scan study. Am Rev Respir Dis 136:730-736

37. Carney DE, Bredenberg CE, Schiller HJ, Picone AL, McCann UG, Gatto LA, Bailey G, Fillinger M, Nieman GF (1999) The mechanism of lung volume change during mechanical ventilation. Am J Respir Crit Care Med 160:1697-1702

38. Namati E, Thiesse J, de Ryk J, McLennan G (2008) Alveolar dynamics during respiration: are the pores of Kohn a pathway to recruitment? Am J Respir Cell Mol Biol 38:572-578

39. Perlman CE, Bhattacharya J (2007) Alveolar expansion imaged by optical sectioning microscopy. J Appl Physiol 103:1037-1044

40. Kollisch-Singule M, Emr B, Smith B, Ruiz C, Roy S, Meng Q, Jain S, Satalin J, Snyder K, Ghosh A, Marx W, Andrews P, Habashi N, Nieman G, Gatto LA (2014) Airway pressure release ventilation reduces conducting airway micro-strain in lung injury. J Am Coll Surg 219:9

41. Dreyfuss D, Soler P, Basset G, Saumon G (1988) High inflation pressure pulmonary edema. Respective effects of high airway pressure, high tidal volume, and positive end-expiratory pressure. Am Rev Respir Dis 137:1159-1164

42. Seah AS, Grant KA, Aliyeva M, Allen GB, Bates JHT (2011) Quantifying the roles of tidal volume and PEEP in the pathogenesis of ventilator-induced lung injury. Ann Biomed Eng 39:1505-1516

43. Steinberg J, Schiller HJ, Halter JM, Gatto LA, Dasilva M, Amato M, McCann UG, Nieman GF (2002) Tidal volume increases do not affect alveolar mechanics in normal lung but cause alveolar overdistension and exacerbate alveolar instability after surfactant deactivation. Crit Care Med 30:2675-2683

44. Cereda M, Xin Y, Kadlecek S, Hamedani H, Rajaei J, Clapp J, Rizi RR (2014) Hyperpolarized gas diffusion MRI for the study of atelectasis and acute respiratory distress syndrome. NMR Biomed 27:1468-1478

45. Chen ZL, Song YL, Hu ZY, Zhang S, Chen YZ (2015) An estimation of mechanical stress on alveolar walls during repetitive alveolar reopening and closure. J Appl Physiol 119:190-201

46. Albaiceta GM, Blanch L (2011) Beyond volutrauma in ARDS: the critical role of lung tissue deformation. Crit Care 15:304

47. Protti A, Andreis DT, Monti M, Santini A, Sparacino CC, Langer T, Votta E, Gatti S, Lombardi L, Leopardi O, Masson S, Cressoni M, Gattinoni L (2013) Lung stress and strain during mechanical ventilation: any difference between statics and dynamics? Crit Care Med 41:1046-1055

48. Protti A, Andreis DT, Milesi M, lapichino GE, Monti M, Comini B, Pugni P, Melis V, Santini A, Dondossola D, Gatti S, Lombardi L, Votta E, Carlesso E, Gattinoni L (2015) Lung anatomy, energy load, and ventilator-induced lung injury. Intensive Care Med Exp 3:34 
49. Steinberg JM, Schiller HJ, Halter JM, Gatto LA, Lee HM, Pavone LA, Nieman GF (2004) Alveolar instability causes early ventilator-induced lung injury independent of neutrophils. Am J Respir Crit Care Med 169:57-63

50. Borges JB, Costa EL, Suarez-Sipmann F, Widstrom C, Larsson A, Amato M, Hedenstierna G (2014) Early inflammation mainly affects normally and poorly aerated lung in experimental ventilator-induced lung injury*. Crit Care Med 42:e279-287

51. Wellman TJ, Winkler T, Costa EL, Musch G, Harris RS, Zheng H, Venegas JG, Vidal Melo MF (2014) Effect of local tidal lung strain on inflammation in normal and lipopolysaccharide-exposed sheep*. Crit Care Med 42:e491-500

52. Albert RK (2012) The role of ventilation-induced surfactant dysfunction and atelectasis in causing acute respiratory distress syndrome. Am J Respir Crit Care Med 185:702-708

53. Fanelli V, Mascia L, Puntorieri V, Assenzio B, Elia V, Fornaro G, Martin EL, Bosco M, Delsedime L, Fiore T, Grasso S, Ranieri VM (2009) Pulmonary atelectasis during low stretch ventilation: "open lung" versus "lung rest" strategy. Crit Care Med 37:1046-1053

54. Serpa Neto A, Cardoso SO, Manetta JA, Pereira VG, Esposito DC, Pasqualucci Mde O, Damasceno MC, Schultz MJ (2012) Association between use of lung-protective ventilation with lower tidal volumes and clinical outcomes among patients without acute respiratory distress syndrome: a meta-analysis. JAMA 308:1651-1659

55. Wolthuis EK, Vlaar AP, Choi G, Roelofs JJ, Juffermans NP, Schultz MJ (2009) Mechanical ventilation using non-injurious ventilation settings causes lung injury in the absence of pre-existing lung injury in healthy mice. Crit Care 13:R1

56. Fuld MK, Easley RB, Saba OI, Chon D, Reinhardt JM, Hoffman EA, Simon BA (2008) CT-measured regional specific volume change reflects regional ventilation in supine sheep. J Appl Physiol 104:1177-1184

57. Reinhardt JM, Ding K, Cao K, Christensen GE, Hoffman EA, Bodas SV (2008) Registration-based estimates of local lung tissue expansion compared to xenon CT measures of specific ventilation. Med Image Anal 12:752-763

58. Kaczka DW, Cao K, Christensen GE, Bates JH, Simon BA (2011) Analysis of regional mechanics in canine lung injury using forced oscillations and 3D image registration. Ann Biomed Eng 39:1112-1124

59. Slutsky AS, Villar J, Pesenti A (2016) Happy 50th birthday ARDS! Intensive Care Med 42:637-639

60. Nieman GF, Gatto LA, Bates JH, Habashi NM (2015) Mechanical ventilation as a therapeutic tool to reduce ARDS incidence. Chest 148:1396-1404

61. Fernandez Mondejar E, Vazquez Mata G, Cardenas A, Mansilla A, Cantalejo F, Rivera R (1996) Ventilation with positive end-expiratory pressure reduces extravascular lung water and increases lymphatic flow in hydrostatic pulmonary edema. Crit Care Med 24:1562-1567

62. Ochiai R (2015) Mechanical ventilation of acute respiratory distress syndrome. J Intensive Care 3:25

63. Brower RG, Lanken PN, Maclntyre N, Matthay MA, Morris A, Ancukiewicz M, Schoenfeld D, Thompson BT, National Heart L, Blood Institute ACTN (2004) Higher versus lower positive end-expiratory pressures in patients with the acute respiratory distress syndrome. N Engl J Med 351:327-336

64. Briel M, Meade M, Mercat A, Brower RG, Talmor D, Walter SD, Slutsky AS, Pullenayegum E, Zhou Q, Cook D, Brochard L, Richard JC, Lamontagne F, Bhatnagar N, Stewart TE, Guyatt G (2010) Higher vs lower positive endexpiratory pressure in patients with acute lung injury and acute respiratory distress syndrome: systematic review and meta-analysis. JAMA 303:865-873

65. Nelson LD (1996) High-inflation pressure and positive end-expiratory pressure. Injurious to the lung? No. Crit Care Clin 12:603-625

66. Gattinoni L, Carlesso E, Brazzi L, Caironi P (2010) Positive end-expiratory pressure. Curr Opin Crit Care 16:39-44

67. Ambrosio AM, Luo R, Fantoni DT, Gutierres C, Lu Q, Gu WJ, Otsuki DA, Malbouisson LM, Auler JO Jr, Rouby J J Experimental ASG (2012) Effects of positive end-expiratory pressure titration and recruitment maneuver on lung inflammation and hyperinflation in experimental acid aspiration-induced lung injury. Anesthesiology 117:1322-1334

68. Kallet RH, Campbell AR, Dicker RA, Katz JA, Mackersie RC (2006) Effects of tidal volume on work of breathing during lung-protective ventilation in patients with acute lung injury and acute respiratory distress syndrome. Crit Care Med 34:8-14

69. Chiumello D, Cressoni M, Carlesso E, Caspani ML, Marino A, Gallazzi E, Caironi P, Lazzerini M, Moerer O, Quintel M, Gattinoni L (2014) Bedside selection of positive end-expiratory pressure in mild, moderate, and severe acute respiratory distress syndrome. Crit Care Med 42:252-264

70. Borges JB, Okamoto VN, Matos GF, Caramez MP, Arantes PR, Barros F, Souza CE, Victorino JA, Kacmarek RM, Barbas CS, Carvalho CR, Amato MB (2006) Reversibility of lung collapse and hypoxemia in early acute respiratory distress syndrome. Am J Respir Crit Care Med 174:268-278

71. Meade MO, Cook DJ, Guyatt GH, Slutsky AS, Arabi YM, Cooper DJ, Davies AR, Hand LE, Zhou Q, Thabane L, Austin P, Lapinsky S, Baxter A, Russell J, Skrobik Y, Ronco JJ, Stewart TE, Lung open ventilation study I (2008) Ventilation strategy using low tidal volumes, recruitment maneuvers, and high positive end-expiratory pressure for acute lung injury and acute respiratory distress syndrome: a randomized controlled trial. JAMA 299:637-645

72. Mercat A, Richard JC, Vielle B, Jaber S, Osman D, Diehl JL, Lefrant JY, Prat G, Richecoeur J, Nieszkowska A, Gervais C, Baudot J, Bouadma L, Brochard L, Expiratory Pressure Study G (2008) Positive end-expiratory pressure setting in adults with acute lung injury and acute respiratory distress syndrome: a randomized controlled trial. JAMA 299:646-655

73. Gattinoni L, Caironi P (2008) Refining ventilatory treatment for acute lung injury and acute respiratory distress syndrome. JAMA 299:691-693

74. Goligher EC, Kavanagh BP, Rubenfeld GD, Adhikari NK, Pinto R, Fan E, Brochard L, Granton JT, Mercat A, Marie Richard JC, Chretien JM, Jones GL, Cook DJ, Stewart TE, Slutsky AS, Meade MO, Ferguson ND (2014) Oxygenation response to positive end-expiratory pressure predicts mortality in acute respiratory distress syndrome. A secondary analysis of the LOVS and ExPress trials. Am J Respir Crit Care Med 190:70-76

75. Nuckton TJ, Alonso JA, Kallet RH, Daniel BM, Pittet JF, Eisner MD, Matthay MA (2002) Pulmonary dead-space fraction as a risk factor for death in the acute respiratory distress syndrome. N Engl J Med 346:1281-1286

76. Cepkova M, Kapur V, Ren X, Quinn T, Zhuo H, Foster E, Liu KD, Matthay MA (2007) Pulmonary dead space fraction and pulmonary artery systolic pressure as early predictors of clinical outcome in acute lung injury. Chest 132:836-842

77. Suarez-Sipmann F, Bohm SH, Tusman G (2014) Volumetric capnography: the time has come. Curr Opin Crit Care 20:333-339 
78. Maisch S, Reissmann H, Fuellekrug B, Weismann D, Rutkowski T, Tusman G, Bohm SH (2008) Compliance and dead space fraction indicate an optimal level of positive end-expiratory pressure after recruitment in anesthetized patients. Anesth Analg 106:175-181, table of contents

79. Tusman G, Suarez-Sipmann F, Bohm SH, Pech T, Reissmann H, Meschino G, Scandurra A, Hedenstierna G (2006) Monitoring dead space during recruitment and PEEP titration in an experimental model. Intensive Care Med 32:1863-1871

80. Yang Y, Huang Y, Tang R, Chen Q, Hui X, Li Y, Yu Q, Zhao H, Qiu H (2014) Optimization of positive end-expiratory pressure by volumetric capnography variables in lavage-induced acute lung injury. Respiration 87:75-83

81. Lachmann B (1992) Open up the lung and keep the lung open. Intensive Care Med 18:319-321

82. Gattinoni L, Pesenti A, Bombino M, Baglioni S, Rivolta M, Rossi F, Rossi G, Fumagalli R, Marcolin R, Mascheroni D et al (1988) Relationships between lung computed tomographic density, gas exchange, and PEEP in acute respiratory failure. Anesthesiology 69:824-832

83. Gattinoni L, Bombino M, Pelosi P, Lissoni A, Pesenti A, Fumagalli R, Tagliabue M (1994) Lung structure and function in different stages of severe adult respiratory distress syndrome. JAMA 271:1772-1779

84. Caironi P, Langer T, Gattinoni L (2008) Acute lung injury/acute respiratory distress syndrome pathophysiology: what we have learned from computed tomography scanning. Curr Opin Crit Care 14:64-69

85. Caironi P, Cressoni M, Chiumello D, Ranieri M, Quintel M, Russo SG, Cornejo R, Bugedo G, Carlesso E, Russo R, Caspani L, Gattinoni L (2010) Lung opening and closing during ventilation of acute respiratory distress syndrome. Am J Respir Crit Care Med 181:578-586

86. Blankman P, Shono A, Hermans BJ, Wesselius T, Hasan D, Gommers D (2016) Detection of optimal PEEP for equal distribution of tidal volume by volumetric capnography and electrical impedance tomography during decreasing levels of PEEP in post cardiac-surgery patients. Br J Anaesth 116:862-869

87. Bikker IG, Leonhardt S, Reis Miranda D, Bakker J, Gommers D (2010) Bedside measurement of changes in lung impedance to monitor alveolar ventilation in dependent and non-dependent parts by electrical impedance tomography during a positive end-expiratory pressure trial in mechanically ventilated intensive care unit patients. Crit Care 14:R100

88. Liu S, Tan L, Moller K, Frerichs I, Yu T, Liu L, Huang Y, Guo F, Xu J, Yang Y, Qiu H, Zhao Z (2016) Identification of regional overdistension, recruitment and cyclic alveolar collapse with electrical impedance tomography in an experimental ARDS model. Crit Care 20:119

89. Wolf GK, Gomez-Laberge C, Rettig JS, Vargas SO, Smallwood CD, Prabhu SP, Vitali SH, Zurakowski D, Arnold JH (2013) Mechanical ventilation guided by electrical impedance tomography in experimental acute lung injury. Crit Care Med 41:1296-1304

90. Deans KJ, Minneci PC, Cui X, Banks SM, Natanson C, Eichacker PQ (2005) Mechanical ventilation in ARDS: one size does not fit all. Crit Care Med 33:1141-1143

91. Suter PM, Fairley B, Isenberg MD (1975) Optimum end-expiratory airway pressure in patients with acute pulmonary failure. N Engl J Med 292:284-289

92. Chiew YS, Chase JG, Shaw GM, Sundaresan A, Desaive T (2011) Model-based PEEP optimisation in mechanical ventilation. Biomed Eng Online 10:111

93. Suarez-Sipmann F, Bohm SH, Tusman G, Pesch T, Thamm O, Reissmann H, Reske A, Magnusson A, Hedenstierna G (2007) Use of dynamic compliance for open lung positive end-expiratory pressure titration in an experimental study. Crit Care Med 35:214-221

94. Amato MB, Barbas CS, Medeiros DM, Schettino Gde P, Lorenzi Filho G, Kairalla RA, Deheinzelin D, Morais C, Fernandes Ede O, Takagaki TY et al (1995) Beneficial effects of the "open lung approach" with low distending pressures in acute respiratory distress syndrome. A prospective randomized study on mechanical ventilation. Am J Respir Crit Care Med 152:1835-1846

95. Amato MB, Barbas CS, Medeiros DM, Magaldi RB, Schettino GP, Lorenzi-Filho G, Kairalla RA, Deheinzelin D, Munoz C, Oliveira R, Takagaki TY, Carvalho CR (1998) Effect of a protective-ventilation strategy on mortality in the acute respiratory distress syndrome. N Engl J Med 338:347-354

96. Schiller HJ, Steinberg J, Halter J, McCann U, DaSilva M, Gatto LA, Carney D, Nieman G (2003) Alveolar inflation during generation of a quasi-static pressure/volume curve in the acutely injured lung. Crit Care Med 31:1126-1133

97. DiRocco JD, Carney DE, Nieman GF (2007) Correlation between alveolar recruitment/derecruitment and inflection points on the pressure-volume curve. Intensive Care Med 33:1204-1211

98. Albaiceta GM, Taboada F, Parra D, Luyando LH, Calvo J, Menendez R, Otero J (2004) Tomographic study of the inflection points of the pressure-volume curve in acute lung injury. Am J Respir Crit Care Med 170:1066-1072

99. Loring SH, Pecchiari M, Della Valle P, Monaco A, Gentile G, D'Angelo E (2010) Maintaining end-expiratory transpulmonary pressure prevents worsening of ventilator-induced lung injury caused by chest wall constriction in surfactant-depleted rats. Crit Care Med 38:2358-2364

100. Staffieri F, Stripoli T, De Monte V, Crovace A, Sacchi M, De Michele M, Trerotoli P, Terragni P, Ranieri VM, Grasso S (2012) Physiological effects of an open lung ventilatory strategy titrated on elastance-derived end-inspiratory transpulmonary pressure: study in a pig model*. Crit Care Med 40:2124-2131

101. Talmor D, Sarge T, Malhotra A, O'Donnell CR, Ritz R, Lisbon A, Novack V, Loring SH (2008) Mechanical ventilation guided by esophageal pressure in acute lung injury. N Engl J Med 359:2095-2104

102. Grasso S, Terragni P, Birocco A, Urbino R, Del Sorbo L, Filippini C, Mascia L, Pesenti A, Zangrillo A, Gattinoni L, Ranieri VM (2012) ECMO criteria for influenza A (H1N1)-associated ARDS: role of transpulmonary pressure. Intensive Care Med 38:395-403

103. Huang Y, Tang R, Chen Q, Pan C, Liu S, Hui X, Li Y, Yang Y, Ranieri VM, Qiu H (2016) How much esophageal pressure-guided end-expiratory transpulmonary pressure is sufficient to maintain lung recruitment in lavageinduced lung injury? J Trauma Acute Care Surg 80:302-307

104. Fish E, Novack V, Banner-Goodspeed VM, Sarge T, Loring S, Talmor D (2014) The Esophageal Pressure-Guided Ventilation 2 (EPVent2) trial protocol: a multicentre, randomised clinical trial of mechanical ventilation guided by transpulmonary pressure. BMJ Open 4:e006356 
105. Ranieri VM, Zhang H, Mascia L, Aubin M, Lin CY, Mullen JB, Grasso S, Binnie M, Volgyesi GA, Eng P, Slutsky AS (2000) Pressure-time curve predicts minimally injurious ventilatory strategy in an isolated rat lung model. Anesthesiology 93:1320-1328

106. Terragni PP, Filippini C, Slutsky AS, Birocco A, Tenaglia T, Grasso S, Stripoli T, Pasero D, Urbino R, Fanelli V, Faggiano C, Mascia L, Ranieri VM (2013) Accuracy of plateau pressure and stress index to identify injurious ventilation in patients with acute respiratory distress syndrome. Anesthesiology 119:880-889

107. Grasso S, Stripoli T, De Michele M, Bruno F, Moschetta M, Angelelli G, Munno I, Ruggiero V, Anaclerio R, Cafarelli A, Driessen B, Fiore T (2007) ARDSnet ventilatory protocol and alveolar hyperinflation: role of positive end-expiratory pressure. Am J Respir Crit Care Med 176:761-767

108. Formenti P, Graf J, Santos A, Gard KE, Faltesek K, Adams AB, Dries DJ, Marini JJ (2011) Non-pulmonary factors strongly influence the stress index. Intensive Care Med 37:594-600

109. Habashi NM (2005) Other approaches to open-lung ventilation: airway pressure release ventilation. Crit Care Med 33:S228-240

110. Jain SV, Kollisch-Singule M, Sadowitz B, Dombert L, Satalin J, Andrews P, Gatto LA, Nieman GF, Habashi NM (2016) The 30-year evolution of airway pressure release ventilation (APRV). Intensive Care Med Exp 4:11

111. Kollisch-Singule M, Emr B, Smith B, Roy S, Jain S, Satalin J, Snyder K, Andrews P, Habashi N, Bates J, Marx W, Nieman G, Gatto LA (2014) Mechanical breath profile of airway pressure release ventilation: the effect on alveolar recruitment and microstrain in acute lung injury. JAMA Surg 149:1138-1145

112. Kollisch-Singule M, Jain S, Andrews P, Smith BJ, Hamlington-Smith KL, Roy S, DiStefano D, Nuss E, Satalin J, Meng Q, Marx W, Bates JH, Gatto LA, Nieman GF, Habashi NM (2015) Effect of Airway pressure release ventilation on dynamic alveolar heterogeneity. JAMA Surg 151:1-9

113. Roy S, Habashi N, Sadowitz B, Andrews P, Ge L, Wang G, Roy P, Ghosh A, Kuhn M, Satalin J, Gatto LA, Lin X, Dean DA, Vodovotz Y, Nieman G (2013) Early airway pressure release ventilation prevents ARDS-a novel preventive approach to lung injury. Shock 39:28-38

114. Andrews PL, Shiber JR, Jaruga-Killeen E, Roy S, Sadowitz B, O'Toole RV, Gatto LA, Nieman GF, Scalea T, Habashi NM (2013) Early application of airway pressure release ventilation may reduce mortality in high-risk trauma patients: a systematic review of observational trauma ARDS literature. J Trauma Acute Care Surg 75:635-641

115. Kacmarek RM, Villar J, Sulemanji D, Montiel R, Ferrando C, Blanco J, Koh Y, Soler JA, Martínez D, Hernández M, Tucci M, Borges JB, Lubillo S, Santos A, Araujo JB, Amato MBP, Suárez-Sipmann F, the Open Lung Approach N (2016) Open lung approach for the acute respiratory distress syndrome: a pilot, randomized controlled trial*. Crit Care Med 44:32-42

116. Fung YC (1975) Stress, deformation, and atelectasis of the lung. Circ Res 37:481-496

117. Taskar V, John J, Evander E, Robertson B, Jonson B (1997) Surfactant dysfunction makes lungs vulnerable to repetitive collapse and reexpansion. Am J Respir Crit Care Med 155:313-320

118. Mead J, Takishima T, Leith D (1970) Stress distribution in lungs: a model of pulmonary elasticity. J Appl Physiol 28:596-608

119. Pilkey WD, Peterson RE (1997) Peterson's stress concentration factors. Wiley, New York

\section{Submit your manuscript to a SpringerOpen ${ }^{\circ}$ journal and benefit from:}

- Convenient online submission

- Rigorous peer review

- Immediate publication on acceptance

- Open access: articles freely available online

- High visibility within the field

- Retaining the copyright to your article

Submit your next manuscript at $>$ springeropen.com 